tion may be unsuitable in a particular school either because the syllabus is so restricted that the last year's work tends to be a mere repetition (sometimes with a minimum of practical work) of what has gone before, or because the syllabus in a particular subject-chemistry, for examplecovers so wide a field that the teachers in the limited time available practically confine themselves to this subject alone, and in dealing with it are forced back on mere bookwork and informational teaching

Relation of Theoretical to Practical Teaching.

Attention has been frequently directed in the reports of inspectors to the necessity of establishing a right relation between the theoretical and practical teaching of science. $\mathrm{By}$ this is meant, not only that the two modes of treatment should be closely associated with one another, but that they should be placed in their right order. In this important matter there has been a notable improvement in the methods of teaching followed in the schools, and criticism in this region is likely in the future to be more concerned with details than with matters of principle. Though opinions differ as to the precise methods by which the desired results are to be secured, it is now very widely recognised that the teaching of a class should, so far as possible, be based on the practical work done by the members of the class. As a fact, lectures have largely given place in elementary teaching to class discussions on the practical work assisted by occasional demonstrations, and the change has been beneficial to the work of the lower and middle forms. In some cases, however (as will be pointed out later on), the practical work has not been supplemented by any adequate discussion of its results. In other cases, the reaction against formal lectures has gone so far as to lead teachers to rely exclusively on the experiments carried out by the class. There is reason to think that when this is done the teaching loses in effectiveness.

Practical work in the lower and middle forms ordinarily follows on a brief discussion of the matter to be investigated, and a written account of the experiment to be carried out is regularly required. Such written accounts should, of course, be the outcome of the pupil's own efforts, and not be, to all intents and purposes, dictated br the teacher or copied from a book. So far as these records are concerned, there has been of late considerable improvement. The mechanical entering up of results in spaces set apart for the purpose, or the filling up of columns under the headings " experiment," "observation," "inference," has nearly disappeared; but more remains to be done in regard both to the form and substance of the record. The idea that there are two standards of composition, one which is appropriate for the English lesson, and another which is good enough for the science laboratory, has not yet been eradicated. But, apart from this, the notebooks often include accounts which are satisfactory in so far as they are purely descriptive, but which fail to show how the "conclusion" follows from the observations recorded or to state what assumptions have been made in the argument. It is not, indeed, uncommon to find conclusions recorded which the pupil's own work quite fails to justify. The "doing", is, in fact, unaccompanied by any honest thinking about what has been done. There is, of course, nothing in this to cause surprise. To expect exactness of thought and accuracy of expression from younger pupils is to expect the ripe fruits of scientific education from those who have but lately begun to enjoy its benefits. If these logical errors never occurred, there would be no need to spend time over teaching " scientific method." It is precisely by seizing the opportunities which such mistakes and omissions afford that the teacher can convey to the pupil valuable lessons in the logic of science.

So far as the actual experimental work is concerned, its value depends in different schools on the extent to which the pupil is encouraged to use his own eves, to apply his powers of reasoning to the problem under consideration, and to criticise his own procedure. The work should, in fact, serve not only to develop the powers of observation and reasoning, but to inculcate " an increasing respect for precision of statement and for that form of veracity which consists in the acknowledgment of difficulties." It is quite NO. 2 I66, VOL. 86$]$ possible for pupils to work through a sei of disconnected experiments and to get little out of it beyond a certain facility in easy manipulation. Work of this kind may be as mechanical and as far removed from being really practical as anything that is done in a classroom. The necessities of the school time-table often lead to the work being broken up into the performance of a series of isolated experiments, one for each lesson period. There is, therefore, the more reason why teachers should be on their guard against the serious danger of making the single experiment the unit of teaching. The exclusion of experiments which are trivial, or of which the results are selfevident, and the occasional adoption of the plan of allowing different groups in a class to work at different though allied experiments, the results obtained by each group being available for the whole class and used in the subsequent discussion, would do much to widen the pupils' experience and give the work a seriousness and importance which it sometimes lacks.

The remarks in the two preceding paragraphs are intended to apply more particularly to the treatment of the practical work in all science subjects in the lower and middle forms. The methods appropriate to the teaching of the higher forms are, in general, much better understood, and need not now be dealt with. But the teaching of botany requires special notice, especially in view of the important position it occupies in the science work of girls' schools.

Teaching of Botany.

Considerable changes have been effected in recent years in the method and scope of botanical teaching. The time given to the purely descriptive work connected with the classification of plants in their natural orders has been greatly curtailed, and it is now common to find included in the course an experimental treatment of plant physiology and some consideration of the question of habitat. There is, too, an increasing tendency to recognise that no adequate study of botany is possible without some knowledge of the elementary facts and principles of chemistry and physics. The broader treatment which the subject now receives, and the substitution of a partially experimental for a purely descriptive method, have led to a healthier development of science teaching in many girls schools. But the new methods have brought with them their own special difficulties, which, in most cases, still await solution. It is rare, for example, to find the experimental work on plant physiology really well done, and the possibilities of the school garden as an adjunct to the laboratory are insufficiently realised by teachers of botany.

Though in connection with this subject it is possible to record a general tendency in the right direction, and in a fair number of instances a real advance, it is still the case that in too many schools botany is regarded somewhat in the light of an accomplishment, making no very serious demands on the pupils' intelligence and requiring little more by way of equipment than a classroom and a bunch of flowers.

In conclusion, it may be stated that if attention has been deliberately directed in some of the foregoing paragraphs to certain existing defects in the teaching of science, this is due to no failure to recognise the excellence of the work which in many secondary schools is being done under the guidance of skilled and experienced teachers.

\section{THE SCIENCE MUSEUM AND THE GEOLOGICAL MUSEUM}

THE report of the Departmental Committee on the Science Museum and the Geological Museum was published a few days ago. The committee was appointed in March, Igro, and its terms of reference were:-"To consider and report upon various questions in regard to the present condition and the future development of the valuable collections comprised in the Board's Science

1 Report of the Departmental Committee on the Science Museum and the Geological Museum. Cd. 562 . (London: Wyman \& Sons, Ltd Price $3 d$. 
Museum at South Kensington and Geological Museum in Jermyn Street. In particular the committee are asked to advise $(a)$ as to the precise educational and other purposes which the collections can best serve in the national interests; $(b)$ as to the lines on which the collections should be arranged and developed, and possibly modified, so as more effectively to fulfil these purposes; and $(c)$ as to the special characteristics which should be possessed by the new buildings which it is hoped will shortly be erected on the South Kensington site to house these collections, so as to enable the latter to be classified and exhibited in the manner most fitted to accomplish the purposes they are intended to fulfil."

The members of the committee were:--Sir Hugh Bell, Bart., chairman ; Dr. J. J. Dobbie, F.R.S.; Sir Archibald Geikie, K.C.B., F.R.S. ; Dr. R. T. Glazebrook, C.B., F.R.S.; Mr. Andrew Laing; the Hon. Sir Schomberg McDonnell, K.C.B., C.V.O.; Sir William Ramsay, K.C.B., F.R.S. ; Prof. W. Ripper; Sir W. H. White, K.C.B., F.R.S.; Mr. F. G. Ogilvie, C.B., secretary.

: he completion of the report is deferred, as the committee is unable to deal in detail with that part of the terms of reference which concerns the adaptation of the general plan of the new buildings to the requirements of classification and exhibition of the collections, until the boundaries of the site are determined. The committee therefore reserves for later consideration and report, when definite information on this point is available, those characteristics of the buildings that will be governed in large measure by special features of the particular site. In the present report the committee sets out the nature, aims, and uses of the collections upon which it proposes to base later recommendations as to the new buildings.

We print below parts of the concluding sections of the report of particular interest.

\section{The Geological Survey Offices and the Museum of Practical Geology.}

The Geological Survey Offices and Library and the Museum of Practical Geology are now cramped by the limitations of the building in Jermyn Street. These institutions, which form parts of a connected whole, and must be kept together, should be grouped, as at present, in a single building. We are convinced that if the necessary space can be allotted at South Kensington, it would be of great advantage to have that building erected as part of the general scheme there. The collections in the Science Museum represent the general principles of geology and geography by examples selected from all regions of the world-the stratigraphical collections in the Jermyn Street Museum deal specially with the geology of the British Isles (see Appendix iv., p. 30). If these two were brought together they would provide the basis of a collection that would be complete as regards stratigraphical and economic geology. Such a collection in the new buildings, with the systematic collection of minerals and the palæontological collections arranged according to their natural affinities in the British Museum (Natural History), would represent at a single centre the whole field of geological science.

In the event of the removal of the Museum of Practica! Geology from its present site, more extended accommodation must be provided for the exhibited specimens. As matters stand now-to refer to one only of the activities of the Geological Survey-the economic collections, which are arranged with special reference to the requirements of the practical man and of the technological student, cannot be properly developed unless more ample galleries are available for them.

\section{Accommodation Required for the Two Museums.}

In dealing with the question of the accommodation that would be required in the new buildings, we must consider both the immediate requirements and the provision to be made for probable future expansion of the collections.

So far as the more immediate needs are concerned, we have prepared an estimate of the minimum floor space which, in our judgment, is necessary for exhibition NO. 2 I66, VOL. 86$]$ galleries, offices, workshops, store-rooms, and demonstration rooms, or other meeting rooms, all properly lit. In this estimate we have assumed that there would be further store accommodation suitable for safe-keeping of objects, although not for their examination. The figures, which are given in Appendix vi. (see p. 32), bring out the following totals:-

Science Museum: Total floor space required in the immediate future, exclusive of entrance halls, staircases, lavatories, cloakrooms, and reserve stores, and in addition to 16,500 square feet already provided in permanent buildings, 300,000 square feet.

Museum of Practical Geology and offices of the Geological Survey : Total floor space required in the immediate future, exclusive of entrance hall, staircases, lavatories, and cloakrooms, and reserve stores, 6o,000 square feet.

Buildings on this scale would provide for such developments as we can now foresee; we think it likely that they would be well utilised within the next ten years, or even in the course of a shorter period, if active steps were taken to make good the deficiencies of the existing collections. At the same time, the buildings could be designed so as to facilitate arrangements for meeting the possible requirements of a more distant future, and whatever space may be set free from time to time by revision of the collections, the building scheme adopted now shnuld provide for ultimate extension of the floor space beyond the area we have stated. With this matter we shall deal further in a later report when we can discuss it with full knowledge of the site available.

\section{General Statement.}

In most of the departments of science and its applications, the museums on which we have been asked to report contain much that is of great historical interest and value. They are rich in specimens, instruments, machines, and models, selected and exhibited in such a manner as to repay systematic examination by the student. They have shown what skilful museum exposition can do to promote an intelligent appreciation of the leading facts and principles of science and of the ways in which invention has applied these to the furtherance of the industrial welfare of the world. In many sections, however, the coliections are now far below the standard which it is clear they ought to reach in these matters, and their proper organisation is impossible in the existing accommodation. When suitable buildings are provided on the scale we have indicated, there will be full opportunity and encouragement for working up all the departments, and more frequent gifts and loans will doubtless quickly fill many of the gaps that are now obvious. Some gaps, indeed, would be filled at once by objects which the governors of the Imperial College of Science and Technology are prepared to present to the museum.

In other departments of knowledge, the British Museum and the Victoria and Albert Museum have set a high standard for the national provision of museum facilities. In the domain of science, the requirements of most of the branches of natural history are already admirably provided for at South Kensington in the Natural History Museum. In no way overlapping or duplicating the functions of these great institutions, but representing aspects of human activity which lie outside their scope, not less ample provision is necessary for those departments of knowledge, invention, and discovery the needs of which have been brought so vividly before us in our inquiry, and we are of opinion that no scheme for a national science niuseum can be regarded as satisfactory unless it provides the buildings necessary for affording to science and the industries all the assistance a museum can give. A science museum in which all branches of physical science, pure and applied, and the scientific and economic work of the Geological Survey, shall be adequately illustrated in close proximity to the other great museums at South Kensington will, we believe, be of incalculable benefit alike to intellectual progress and to industrial development, and will be recognised as an institution of which the country may well be nroud. 